\title{
The Relationship Between Weightlifting Trainers' Leadership Characteristics and their Leadership Strength as per the Perceptions of Athletes
}

\section{Mevlüt Gönen', Murat Kul², Ismail Karataș3,}

${ }^{1}$ Department of Coaching Education, High School of Physical Education and Sports, Bayburt University

${ }^{2}$ Department of Sports Management, High School of Physical Education and Sports, Bayburt University

${ }^{3}$ Department of Physical Education, High School of Physical Education and Sports, Bayburt University

Study Area: Bayburt, Turkey

Coordinates: $40^{\circ} 15^{\prime} 35 ; \mathrm{N} ; 40^{\circ} 13^{\prime} 40 ; \mathrm{E}$

Key words: Weightlifting, Trainer, Leadership, Leadership Characteristics, Leadership Strength

\section{Introduction:}

A trainer is described as a sportsperson who assembles the corporate knowledge and experiences he has acquired in his professional life, guides the athletes according to their abilities, trains them and prepares them for competitions. Although unwritten, trainers' job descriptions also include leading the athletes (Dogan, 2005). Leadership is conceptually defined as the process of leading individuals or a group by influencing a common goal. The person carrying out this process is called the leader (Barrow, 1977).

When we talk on the factors that cause a leader to be effective, it is essential to consider the concept of power to refer to the process of influencing subordinates, superiors and other stakeholders. Power is also an inevitable part of the organisation process (Zaleznik, 1998). Power is an integral part of leadership as leadership is defined as the necessity of power employed to influence individuals in this organisational and a kind of social influence process (Northouse, 2007).

French \& Raven (1959) suggested that there are five different power factors. "Reward Power (1)" is the ability to reward group members. "Coercive power (2)" is the ability to apply one or more punishment methods if necessary. "Legitimate power (3)" is the ability of a person to exercise his or her authority and position over an organisation, group or team. "Expert power (4)" is to be equipped on a subject-specific to a particular area. "Referent power (5)" is the power possessed by those who follow the leader or those who are loved and respected by group members (French \& Raven, 1959).

\section{Abstract}

The research was designed with correlational research model, one of the quantitative approaches. In the selection of the research group, purposeful sampling approaches and convenience sampling method were applied. The research group consists of 351 weightlifters, 136 women and 215 men. The data were obtained using the "Personal Information Form", "Sports Leadership Scale (SLS)" and "Sport Leadership Strength Scale-Other (SLSS-O)". Relevant Statistical analysis was applied to interpret the data. Consequently, low-level positive correlations between SLS and all sub-dimension mean scores of SLSS-O were determined.

Chelladurai (1984), associating power factors with leadership behaviours, stated that authoritarian leader behaviours are similar to actions, coercive power and legitimate power, democratic behaviours, expert power, social support approach, referent power, positive feedback and reward power. In addition to these data, in many studies, coercive and reward powers, referent power with social support, legitimate and expert powers with internalisation, legitimate, reward and coercive powers with the position, Self-Leadership personal power and expert power have been associated with obedience (Kelman, 1958; Yukl \& Falbe 1991; Slack, 1997; Gayretli \& Çelik, 2020).

When the perception of the power of the leader by the group members is considered within the organisation, it is understood that individual or organisational factors play a significant role in the perception of this power more or less. Factors such as corporate culture, climate or personality traits of the leader are influential on perceived power (Meydan, 2010). As a leader, the power of a trainer over the organisation formed in the sports environment is also critical in this context. Based on the relevant data, our study aimed to examine the relationship between weightlifting trainers' leadership strength and leadership traits in line with the perceptions of athletes.

\section{Methodology:}

Within the scope of this quantitative research, a correlational research model was applied to investigate the relationship between two variables consistent with the general purpose of the study.

*Corresponding Author: mevlutgonen@bayburt.edu.tr 
In the selection of the research group, purposeful sampling approaches and convenience sampling method were used. In this context, the research group consists of 351 weightlifters, 136 women and 215 men participating in Naim Süleymanoglu Adults Individual Turkey Weightlifting Championship organised in Manavgat district of Antalya on January 23-26th, 2020.

The scale form prepared by the aims of the research was applied to the athletes in the sample voluntarily. During the application of the data collection tools, the participants were informed on the purpose of the research. After the measurement tools were given to the students, they were provided with the correct answer of the scale form in the presence of the researcher. Personal Information Form, Leadership in Sports Scale, and Leadership Strength in Sports-Other Scale were used to collect research data.

Within the scope of the research, "Personal Information Form" consists of seven items. This form was used to reach findings concerning some demographic variables of the participants (gender, age, education level, and place of residence, monthly income, maternal education level and father's education status).

The Leadership in Sports Scale (SLS), developed by Chelladurai \& Saleh (1980) was applied to evaluate the leadership styles and behaviour patterns perceived by athletes about their trainers. Toros and Tiryaki (2006) carried out Turkish reliability and validity studies of the scale. This five-point Likert type scale consists of 40 items and five sub-dimensions. .8o for "Learning Behavior", .79 for "Democratic Behavior",.41 for "Autocratic Behavior",.75 for "Social Support" and .6o for "Rewarding Behavior" Cronbach's Alpha value was obtained according to the calculated internal consistency coefficients of each subdimension (Toros and Tiryaki, 2006).

Wann et al. (2000) transferred the interpersonal power typology of French and Faven (1959) to sports psychology, and two separate scale forms were developed for athletes and trainers. These are Sports Leadership Strength ScaleSelf (trainer form-SLSS-S) and Sport Leadership Strength Scale-Other (athlete form-SLSS-O). Konter (2007) performed the adaptation of SLSS-O and SLSS-S to Turkish, and the validity and reliability studies of the scales were revealed four power factors. These are coercive, expert, legitimate and referent powers (Konter, 2007). SLSS-O and SLSS-S are Likert-type scales, and the answer given to each item varies between 1 and 9 ( 1 represents 'I do not agree at all', 9 means 'I completely agree'). SLSS-O and SLSS-S consist of 11 items. There were three items in each sub-factor and only two items in the "coercive power". A higher score indicates more excellent leadership power perception. In Turkish culture, SLSS-O's Cronbach Alpha reliability coefficients are $\mathrm{a}=.86$ in coercive power, $\mathrm{a}=.89$ in expert power, $\mathrm{a}=.82$ in legitimate power and $\mathrm{a}=.85$ in referent power. Cronbach Alpha reliability coefficients of SLSS-S in
Turkish culture are $\mathrm{a}=.87$ in coercive power, $\mathrm{a}=.88 \mathrm{in}$ expert power,. 88 in legitimate power and $\mathrm{a}=.86 \mathrm{in}$ referent power (Konter, 2007).

Regarding the structure and statistical properties of the data obtained from the research group, t-test, KruskalWallis test, Spearman Rank Difference Correlation Analysis and Pearson Correlation Analysis were applied in the analysis. Besides, the significance level was accepted as 0.05 in the interpretation of the research findings.

\section{Result:}

In this part of the research, the analysis findings of the relevant data are given in the form of tables and interpreted.

Table-1: Frequency \& percentages of the demographic Variables

\begin{tabular}{lllllll}
\hline Variables & Groups & $\mathrm{f}$ & $\%$ & Groups & $\mathrm{f}$ & $\%$ \\
\hline Gender & Female & 136 & 38.7 & Male & 215 & 61.3 \\
Education & Pri.+Second. & 29 & 8.3 & High School 232 & 66.1 \\
& University & 90 & 25.6 & & & \\
Residence at & Village + Town & 31 & 8.8 & City & 155 & 44.2 \\
& Metropolis & 165 & 47.0 & & & \\
Mothers' Level llliterate & 21 & 6.0 & Literate & 30 & 8.5 \\
of Education & Primary & 101 & 28.8 & Secondary & 103 & 29.3 \\
& High School & 86 & 24.5 & University & 10 & 2.8 \\
Father's Level & Illiterate & 13 & 3.7 & Literate & 29 & 8.3 \\
of Education & Primary & 94 & 26.8 & Secondary & 103 & 29.3 \\
& High School & 95 & 27.1 & University & 17 & 4.8 \\
& $X^{-}$ & ss & & & & \\
Age & 19.128 & 2.7491 & & & \\
Monthly Income Status & 4010.997 & 2265.8271 & & \\
Total Number of People & 351 & & & & \\
\hline
\end{tabular}

Table-1 is self explanatory.

Table-2: Independent Samples t-test Results Regarding SubDimensions of the Scales in Terms of Gender Variable.

\begin{tabular}{|c|c|c|c|c|c|c|c|}
\hline Sub-dimensions & Sex & $\mathrm{n}$ & Mean & St.Dev. & $\mathrm{Sd}$ & $\mathrm{t}$ & $\mathrm{p}$ \\
\hline Learning & Fem. & 136 & 3.8722 & .81833 & 349 & 1.263 & .208 \\
\hline Behaviour & Mal. & 215 & 3.7599 & .80686 & & & \\
\hline Democratic & Fem. & 136 & 3.9608 & .81003 & 349 & 2.098 & ${ }^{*} .037$ \\
\hline Behavior & Male & 215 & 3.7705 & .83863 & & & \\
\hline Autocratic & Fem. & 136 & 3.4471 & .85764 & 349 & 1.017 & .310 \\
\hline Behavior & Male & 215 & $3 \cdot 3516$ & .85614 & & & \\
\hline Social Supp- & Fem. & 136 & 3.7978 & .89998 & 349 & .235 & .814 \\
\hline ort Behavior & Male & 215 & 3.7750 & .87677 & & & \\
\hline Rewarding & Fem. & 136 & 3.8338 & .87553 & 349 & .500 & .617 \\
\hline Behavior & Male & 215 & 3.7870 & .84224 & & & \\
\hline Coercive & Fem. & 136 & 4.6103 & 2.14104 & 349 & .346 & .730 \\
\hline Power & Male & 215 & 4.5279 & 2.19370 & & & \\
\hline N Referent & Fem. & 136 & 6.2696 & $1.9255^{8}$ & 349 & 1.143 & .254 \\
\hline « Power & Male & 215 & 6.0217 & 2.01411 & & & \\
\hline Legitimate & Fem. & 136 & 6.5123 & 1.82344 & 349 & 1.837 & .067 \\
\hline Power & Male & 215 & 6.1178 & 2.04024 & & & \\
\hline Expert & Fem. & 136 & 6.5441 & 1.88116 & 349 & $.55^{8}$ & .577 \\
\hline Power & Male & 215 & 6.4279 & 1.91346 & & & \\
\hline
\end{tabular}

"Democratic Behavior" sub-dimension scores of the leadership characteristics in sports scale (SLS) by gender. This difference is in favour of the female participants. Thus, it is assumed that female athletes perceive the behaviour of the trainer as more democratic 
TECHNOSCIENCE ARTICLE

than male athletes do.

Table-3: Spearman rank differences correlation analysis results between age variable and sub-dimensions of leadership (behaviour) in sports scale $\left({ }^{*} \mathrm{P}<.05\right)$

\begin{tabular}{lllllll} 
Variable & Scale & Learning & Democratic & Autocratic & Social Support & Rewarding \\
\hline Age & $\mathrm{r}$ & .059 & .072 & .038 & .060 & .019 \\
& $\mathrm{p}$ & .272 & .180 & .478 & .265 & .720 \\
& $\mathrm{n}$ & 351 & 351 & 351 & 351 & 351 \\
\hline
\end{tabular}

No statistically significant relationship was observed between the age variable of the participants and the mean scores of the SLS sub-dimensions ( $\mathrm{p}>0.05)$.

Table-4: Spearman rank differences correlation analysis results between age variable and sub-dimensions of leadership (power) strength scale. $\left({ }^{*} \mathrm{P}<.05\right)$

\begin{tabular}{llllll}
\hline Variable & Scale & Coercive Power & Referent Power & \multicolumn{3}{l}{ Legitimate Power } & Expert Power \\
\hline Age & $\mathrm{r}$ & .059 & .072 & .038 .060 & .019 \\
& $\mathrm{p}$ & .272 & .180 & .478 .265 & .720 \\
& $\mathrm{n}$ & 351 & 351 & 351351 & 351 \\
\hline
\end{tabular}

No statistically significant relationship was observed between the age variable of the participants and the mean scores of the SLSS-O sub-dimensions (Table-4).

Table-5: Kruskal-Wallis test results related to the subdimensions of the scales in terms of education status variable..

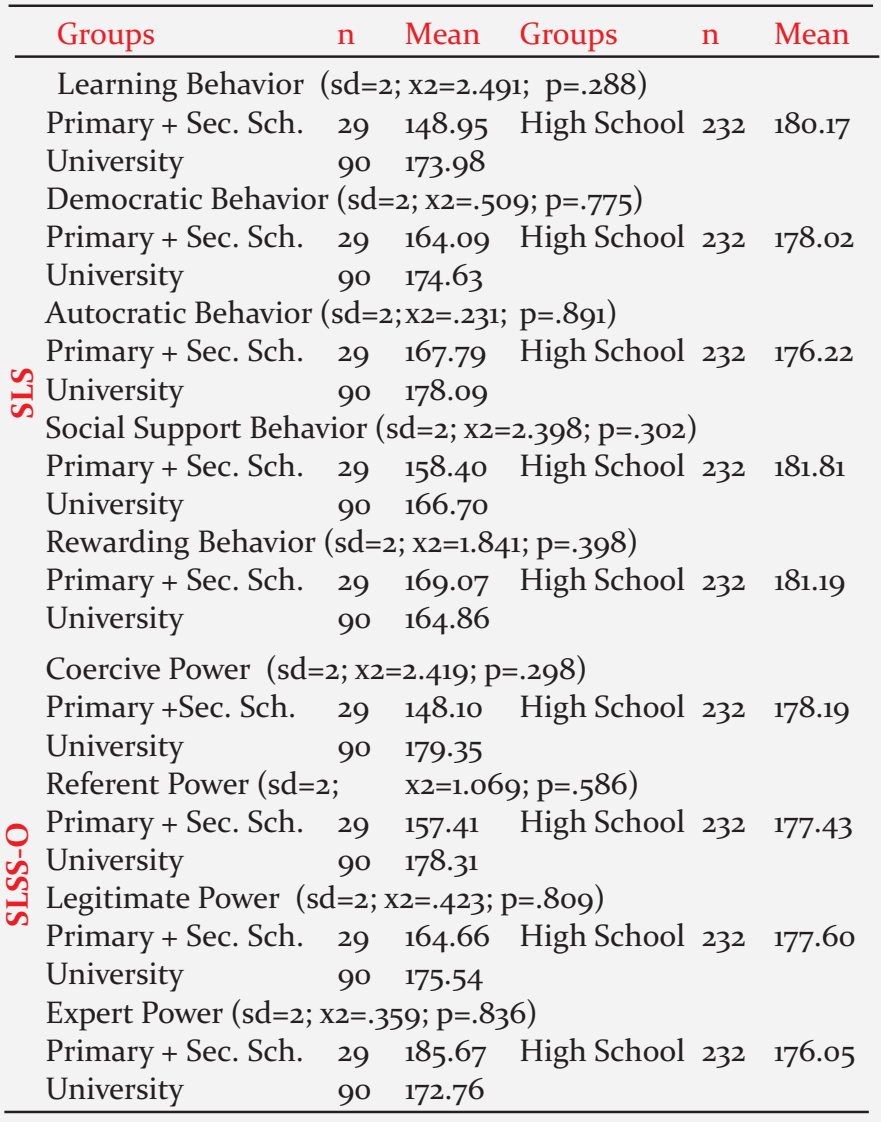

No statistically significant difference was found between the sub-dimension mean scores of the research scales in terms of the educational status variable (Table-5).

Table-6: Kruskal-wallis test results regarding sub-dimensions of
Ambient Science, 2020: Vol. 07(Sp1); 333-338 DOI:10.21276/ambi.2020.07.sp1.ta14

\begin{tabular}{|c|c|c|c|c|c|}
\hline Groups & $\mathrm{n}$ & Mean & Groups & $\mathrm{n}$ & Mean \\
\hline \multicolumn{6}{|c|}{ Learning Behavior $(\mathrm{sd}=2 ; \mathrm{x} 2=4.192 ; \mathrm{p}=.123)$} \\
\hline Village + Town & 31 & 140.44 & City & 155 & 180.00 \\
\hline Metropolis & 165 & 178.92 & & & \\
\hline \multicolumn{6}{|c|}{ Democratic Behavior $(\mathrm{sd}=2 ; \mathrm{x} 2=1.199 ; \mathrm{p}=.549)$} \\
\hline Village + Town & 31 & 166.19 & City & 155 & 171.46 \\
\hline Metropolis & 165 & 182.10 & & & \\
\hline A Autocratic Behavior & $(\mathrm{sd}=$ & $=2 ; x 2=5.6$ & $687 ; p=.058)$ & & \\
\hline Village + Town & & 150.37 & City & 155 & 167.57 \\
\hline Metropolis & 165 & 188.73 & & & \\
\hline \multicolumn{6}{|c|}{ Social Support Behavior $(\mathrm{sd}=2 ; \mathrm{x} 2=3.772 ; \mathrm{p}=.152$ ) } \\
\hline Village + Town & & 148.87 & City & 155 & 171.88 \\
\hline Metropolis & 165 & 184.96 & & & \\
\hline \multicolumn{6}{|c|}{ Rewarding Power Behavior $(\mathrm{sd}=2 ; \mathrm{x} 2=.111 ; \mathrm{p}=.946)$} \\
\hline Village + Town & 31 & 171.71 & City & 155 & 175.12 \\
\hline Metropolis & 165 & 177.63 & & & \\
\hline \multicolumn{6}{|c|}{ Coercive Power $(\mathrm{sd}=2 ; \mathrm{x} 2=3.339 ; \mathrm{p}=.188)$} \\
\hline Village + Town & 31 & 159.02 & City & 155 & 168.66 \\
\hline Metropolis & 165 & 186.08 & & & \\
\hline \multicolumn{6}{|c|}{$\approx$ Referent Power $(\mathrm{sd}=2 ; \mathrm{x} 2=.513 ; \mathrm{p}=.774)$} \\
\hline ज Village + Town & 31 & 163.56 & City & 155 & 177.28 \\
\hline Metropolis & 165 & 177.14 & & & \\
\hline \multicolumn{6}{|c|}{ Legitimate Power $(\mathrm{sd}=2 ; \mathrm{x} 2=6.252 ; \mathrm{p}=.044)$} \\
\hline Village + Town & 31 & 132.69 & City & 155 & 181.29 \\
\hline Metropolis & 165 & 179.17 & & City > & Village \\
\hline Expert Power $(\mathrm{sd}=2$; & $\mathrm{x} 2=3$ & $3.010 ; \mathrm{p}=$ & $.222)$ & + Tow & \\
\hline Village + Town & 31 & 158.79 & City & 155 & 185.97 \\
\hline Metropolis & 165 & 169.86 & & & \\
\hline
\end{tabular}

A significant difference was evidenced between city and village + town in favour of participants living in the city. From here, it is assumed that the legitimate power perceptions of the athletes living in the city towards their trainers are higher. No significant difference was observed in other sub-dimensions of the scales (Table-6).

Table-6: Kruskal-wallis test related to the sub-dimensions of the scales in terms of the maternal education status variable

\begin{tabular}{|c|c|c|c|c|c|}
\hline Groups & $\mathrm{n}$ & Mean & Groups & $\mathrm{n}$ & Mean \\
\hline \multicolumn{3}{|c|}{ Learning Behavior $(\mathrm{sd}=5$; } & \multicolumn{3}{|l|}{$\mathrm{x} 2=8.319 ; \mathrm{p}=.140)$} \\
\hline Illiterate & 21 & 214.05 & Literate & 30 & 173.77 \\
\hline Primary School & 101 & 186.49 & Seco & 103 & 168.98 \\
\hline High School & 86 & 159.17 & Uni & 10 & 214.00 \\
\hline \multicolumn{6}{|c|}{$\bar{\sim}$ Democratic Behavior $(\mathrm{sd}=5 ; \mathrm{x} 2=9.400 ; \mathrm{p}=.094)$} \\
\hline Illiterate & 21 & 212.00 & Liter & 30 & 160.55 \\
\hline Sch. & 101 & 192.66 & Sec & 103 & 170.27 \\
\hline High School & 86 & 157.96 & University & 10 & 192.60 \\
\hline \multicolumn{6}{|c|}{ Autocratic Behavior $\quad(\mathrm{sd}=5 ; \mathrm{x} 2=3.035 ; \mathrm{p}=.695)$} \\
\hline Illiterate & 21 & 188.38 & Literate & 30 & 188.83 \\
\hline Sch. & 101 & 167.68 & Sec & 103 & 172.06 \\
\hline High School & 86 & 185.83 & University & 10 & 151.60 \\
\hline \multicolumn{6}{|c|}{ Social Support Behavior $(\mathrm{sd}=5 ; \mathrm{x} 2=4.567 ; \mathrm{p}=.471)$} \\
\hline Illiterate & 21 & 204.24 & Literate & 30 & 171.37 \\
\hline y Sch. & 101 & 186.95 & Seco & 103 & 172.66 \\
\hline High School & 86 & 162.35 & University & 10 & 171.80 \\
\hline \multicolumn{2}{|c|}{ Rewarding Behavior } & $(s d=5$ & $\mathrm{x} 2=6.445$ & \multicolumn{2}{|c|}{$\mathrm{p}=.265)$} \\
\hline Illite & 21 & 204.55 & Lite & 30 & 178.67 \\
\hline Primary Sch. & 101 & 186.92 & Secondory Sch. & 103 & 175.01 \\
\hline
\end{tabular}




\begin{tabular}{|c|c|c|c|c|c|}
\hline High School & 86 & $155 \cdot 58$ & University & 10 & 183.60 \\
\hline \multicolumn{6}{|c|}{ Coercive Power $\left(\mathrm{sd}=5 ; \mathrm{x} 2=13.048^{*} ; \mathrm{p}=.020\right)$ High Sch. $>$ Secondary Sch } \\
\hline Illiterate & 21 & $197 \cdot 48$ & Literate & 30 & 169.55 \\
\hline Primary Sch. & 101 & $177 \cdot 40$ & Secondory Sch. & 103 & 151.92 \\
\hline High School & 86 & 202.70 & University & 10 & $154 \cdot 50$ \\
\hline \multicolumn{6}{|c|}{ Referent Power $(\mathrm{sd}=5 ; \mathrm{x} 2=1.525 ; \mathrm{p}=.910)$} \\
\hline Illiterate & 21 & 170.19 & Literate & 30 & 175.18 \\
\hline Primary Sch. & 101 & 172.16 & Secondory Sch. & 103 & 171.20 \\
\hline High School & 86 & 186.45 & University & 10 & 188.90 \\
\hline \multicolumn{4}{|c|}{ Legitimate Power $(s d=5 ; x 2=5.165$; } & \multicolumn{2}{|c|}{$\mathrm{p}=.396)$} \\
\hline Illiterate & 21 & 186.88 & Literate & 30 & 155.97 \\
\hline Primary Sch. & 101 & 169.20 & Secondory Sch. & 103 & 170.03 \\
\hline High School & 86 & 192.36 & University & 10 & 202.65 \\
\hline \multicolumn{6}{|c|}{ Expert Power $(\mathrm{sd}=5 ; \mathrm{x} 2=8.356 ; \mathrm{p}=.138)$} \\
\hline Illiterate & 21 & 141.33 & Literate & 30 & 162.92 \\
\hline Primary Sch. & 101 & 181.71 & Secondory Sch. & 103 & 163.52 \\
\hline High School & 86 & 196.15 & University & 10 & 185.65 \\
\hline
\end{tabular}

A statistically significant difference between the mean scores of the "coercive power" sub-dimension of SLSS-O in terms of the maternal education variable was discovered which was in favour of the participants whose mother's education status was high school and middle school, and the participants whose mother's education level was high school. No statistically significant difference was observed in other sub-dimensions of the scales (Table-7).

Table-8: Kruskal-wallis test results related to sub-dimensions of scales in terms of father's education status variable.

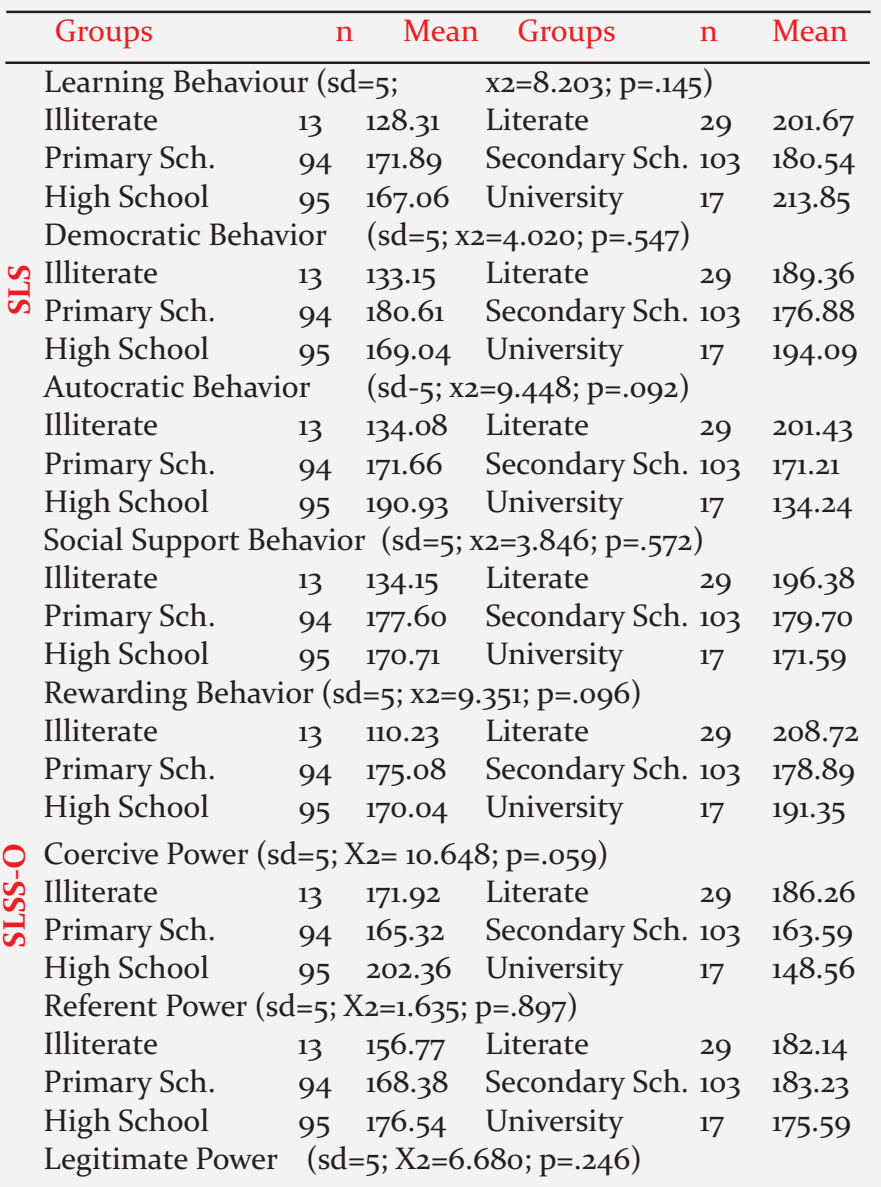

$\begin{array}{lcclll}\text { Illiterate } & 13 & 161.62 & \text { Literate } & 29 & 197.90 \\ \text { Primary Sch. } & 94 & 157.42 & \text { Secondary Sch. } 103 & 176.60 \\ \text { High School } & 95 & 184.00 & \text { University } & 17 & 204.03 \\ \text { Expert Power } & \text { (sd=5; X2=3.824; }=.575 \text { ) } & & \\ \text { Illiterate } & 13 & 138.77 & \text { Literate } & 29 & 172.33 \\ \text { Primary Sch. } & 94 & 172.69 & \text { Secondary Sch. } 103 & 176.74 \\ \text { High School } & 95 & 178.72 & \text { University } & 17 & 209.38\end{array}$

No statistically significant difference between the subscales (Table-8).

Table-9: Rank differences Correlation Analysis between Monthly Income Variable and sub-dimensions of Sports Leadership Scale.

\begin{tabular}{|c|c|c|c|c|c|c|}
\hline Variable & Scale & Learning & Democratic & Autocratic & Social Support & Rewarding \\
\hline \multirow{3}{*}{$\begin{array}{l}\text { Monthly } \\
\text { Income }\end{array}$} & $r$ & -.040 & -.096 & $-.118^{*}$ & -.077 & -.036 \\
\hline & $\mathrm{p}$ & .455 & .074 & .027 & .151 & .507 \\
\hline & $\mathrm{n}$ & 351 & 351 & 351 & 351 & 351 \\
\hline
\end{tabular}

A negative relationship between the monthly income variable of the participants and the mean scores of the "Autocratic Behavior" sub-dimension of SLS (Table-9).

Table-10: Spearman rank differences correlation analysis between Monthly Income Variable and Sub-Dimensions of Leadership Strength in Sports Scale

\begin{tabular}{llllll}
\hline Variable & Scale & Coercive & Referent & Legitimate & Expert \\
\hline Monthly & $\mathrm{r}$ & $-.159^{* *}$ & -.067 & -.026 & -.069 \\
Income & $\mathrm{p}$ & .003 & .208 & .632 & .199 \\
& $\mathrm{n}$ & 351 & 351 & 351 & 351 \\
\hline
\end{tabular}

A negative relationship between the monthly income variable of the participants and the mean scores of the “coercive power" sub-dimension of SLSS-O (table-10).

Table-10: Results of Pearson correlation analysis between subdimensions of leadership in sports \& leadership strength in sports

\begin{tabular}{lllllll}
\hline Variable & Scale & \multicolumn{5}{l}{ Learning Democratic Autocratic Social Support Rewarding } \\
\hline Coercive & $\mathrm{r}$ & $.158^{*}$ & $.109^{*}$ & $.260^{*}$ & $.176^{*}$ & $.148^{* *}$ \\
& $\mathrm{p}$ & .003 & .041 & .000 & .001 & .005 \\
& $\mathrm{n}$ & 351 & 351 & 351 & 351 & 351 \\
Referent & $\mathrm{r}$ & $.236^{*}$ & $.225^{*}$ & $.185^{*}$ & $.218^{*}$ & $.228^{*}$ \\
& $\mathrm{p}$ & .000 & .000 & .000 & .000 & .000 \\
& $\mathrm{n}$ & 351 & 351 & 351 & 351 & 351 \\
Legitimate & $\mathrm{r}$ & $.212^{*}$ & $.190^{*}$ & $.237^{*}$ & $.190^{*}$ & $.229^{* *}$ \\
& $\mathrm{p}$ & .000 & .000 & .000 & .000 & .000 \\
Expert & $\mathrm{n}$ & 351 & 351 & 351 & 351 & 351 \\
& $\mathrm{r}$ & $.221^{* *}$ & $.153^{*}$ & $.115^{*}$ & $.207^{*}$ & $.206^{*}$ \\
& $\mathrm{p}$ & .000 & .004 & .032 & .000 & .000 \\
& $\mathrm{n}$ & 351 & 351 & 351 & 351 & 351 \\
\hline
\end{tabular}

\section{Discussion :}

As a result of the analysis, the leadership characteristics and leadership strength of weightlifting trainers perceived by the athletes did not show a significant difference in the subdimensions of both scales according to the variables of the athletes' age and educational status. Related results to our findings, Tozkar (2019) did not detect a statistically significant difference between athletic students' perceptions of leadership power towards their teachers as a leader, and their age, educational status and their 


\section{TECHNOSCIENCE ARTICLE}

perceptions of leadership power for their teachers. Furthermore, in football players, no significant difference was observed between the age variable and the leadership behaviours of the trainers in line with the perceptions of the participants (Besiz, 2016). As a result of the analyses evaluating the leadership characteristics and leadership power perceptions of athletes towards their trainers in terms of gender variable, a significant difference was found in favour of female athletes only in the mean scores of the "Democratic Behavior" sub-dimension of the SLS. Konter (2007) reported a significant difference in SLSS-O's "Power of Expert" sub-dimension scores according to the gender of the athletes. Therefore, female athletes have a higher perception of expert power for their trainers than male athletes. Çetintas (2019) by taking karate trainers as a sample, it was concluded that, contrary to the present findings, the gender variable was not a determining factor on the leadership power perception of the trainer. Thus, Öktem (2015) did not detect a statistically significant difference between perceived leadership behaviours of the trainer according to the gender variable in his study on karateathletes.

In this context, as Reddin (1977) mentioned in the “Three Dimensional Leadership Theory", the leadership process is thought to be related to the competence of the person and the ability to penetrate the perceptions of the members of the organisation.

When the data on the place of residence variable were examined, it was determined that the athletes residing in the city had higher perceptions of the "legitimate Power" sub-dimension of SLSS-O than the athletes living in the village + town did. It is thought that the more formal, prescriptive and authoritarian structure of city life compared to village life affects the perception of athletes towards their trainers in this direction.

According to the data obtained from our research group, a significant difference was found in the "coercive power" sub-dimension of SLSS-O in the mother education variable. This difference is in favour of the athletes whose mother's education level is high school and those who have a secondary school, and those whose mother's education level is high school. Duran (2019) investigated the factors affecting leadership behaviour and perceptions of children at an early age, and as a result, the mother found a significant difference in education status. The family, which is the first structure in which a person's life takes shape, is essential in the formation of personality and leadership qualities of children in this regard (Arslan \& Durmus, 2013). Aslan et al. (2017) support our data. The educational level of family members and their relationships with each other, the life offered to the child, the ways to solve the problems and decision-making styles are the factors that affect the children's approaches and definitions to the concept of leadership. Although all these studies emphasise the
Ambient Science, 2020: Vol. 07(Sp1); 333-338 DOI:10.21276/ambi.2020.07.sp1.ta14

influence of mothers, fathers' influence cannot be underestimated. In the general family structures in our country, the relationship between the father and the child, combined with the collectivist and hierarchical cultural structure, shapes the identity of the leaders with its reflection on the organisational management (Canbolat et al., 2010). The reason for the differing results and findings of our study is the possibility that mothers take a more active role in the lives of their children in family dynamics in the research groups.

A negative and low-level significant relationship was found between the monthly income variable of the participants and the mean scores of SLS's "Autocratic Behavior" and SLSS-O's "Coercive Power". "Coercive power" is the leader's use of his power source for intimidation and mobbing. "Autocratic Behavior", on the other hand, is the mode of behaviour in which all authority and decisionmaking process is in the lead (Wann et al., 200o). In this context, the perception of trainer behaviour as more authoritarian and coercive as the monthly income level decreases in athletes can be explained by the socioeconomic limitations and inadequacies that athletes may feel. Weiss (2002) stated that increasing income level affects people's perceptions in various ways. Adatepe (2018) emphasised the importance of people's socio-economic status on their perception levels. These results coincide with our research data, and it is thought that the income earned by the individual can increase motivation and exhibit behaviour that is more pragmatic and attitude.

Although there were many studies on the leadership and leadership characteristics of the coach in sports (Dale \& Weinberg, 1989; Dwyer \& Fischer, 1990; Brooks et al., 200o; Turman, 2001; Turman \& Schrodt, 2004; Kim \& Cruz, 2016; Turnnidge \& Côté, 2019) There is no study covering the leadership characteristics and leadership power of the trainer at the same time. In this study, which was carried out to fill this gap in the literature, the relationship between the leadership characteristics of weightlifting trainers and their leadership strength was evaluated from the perspective of athletes. As a result of the research, according to the perceptions of the athletes, there was a low level of a positive correlation between leadership in sports and leadership power in sports scales. Thus, it can beassumed that effective and robust leadership characteristics are at the basis of a strong leadership perception. In this sense, it can be concluded that the ability of trainers to exhibit behaviour under the related situation such as educational and instructive behaviour, democratic behaviour, autocratic behaviour, social support behaviour, rewarding behaviour, which are among the effective leadership characteristics, will play a supportive role in being recognized as a strong leader.

As a consequence, new data has been collected that will add scientific results to the literature. However, the study 
results provide a small number of participant data, taking into account constraints on sampling access. For this purpose, it is possible to perform similar research in which the study is extended to include all categories of age and gender, exploring the same relationship with a broad data collection. Moreover, through conducting qualitative and mixed studies, research findings may be diversified.

\section{References:}

Adatepe, E. (2018): Measuring of the Physical Education and Sports School Students' Education Quality Perceptions (Bartin University Example). Bartin University, Institue of Education Sciences, MasterThesis, Bartin.

Arslan, H. \& Durmus, Ö. (2013): A research of leadership behaviors in primary school students. Int. J. Soc. Sci., 6(1):207-228.

Aslan, S., Yalçin, H., Sarp, N. \& Akarçay Ulutas, D. (2017): The effects of parental behavior and social enviroment on leaders. Üsküdar Univers. J. Soc. Sci., 3(4):91-138.

Barrow, J. C. (1977): The variables of leadership: a review and conceptual framework. Acad. Manag. Rev., 2(2):231-251.

Bensiz, A. (2016): Examination of the Leadership Characteristics of Coaches According to the Perceptions of the Amateur Football Players. Bartin University, Institue of Education Sciences, Master Thesis, Bartin.

Brooks, D.D., Ziatz, D., Johnson, B., \& Hollander, D. (200o): Leadership behavior and job responsibilities of NCAA Division 1 A strength and conditioning coaches. J Stren. Cond. Res., 14(4):483-492.

Canbolat, E.Ö., Beraha, A., Çeliksoy, E. \& Türker, Y. (2010): Turkish leader profile: a qualitative research on Turkish political leaders. J. Soc. Human., 2(2):37-45.

Chelladurai, P. (1984): Discrepancy between preference and perception of leadership behavior and satisfaction of athletes in varying sports. J. Sport Psychol., 6:27-41.

Çetintas, Y. (2019): An Investigation of Leadership Orientations of Karate Coaches. Bartin University, Institue of Education Sciences, Master Thesis, Bartin.

Dale, J., \& Weinberg, R.S. (1989): The relationship between coaches' leadership style and burnout. Sport Psychol., 3(1):113.

Dogan, O. (2005): Sports Psychology (2nd Edition). Pub. by: Nobel Publications, Ankara.

Duran, A. (2019): Development of Early Childhood Leadership Scale and the Investigation of the Relationship Between Leadership Qualities of Children and Language Skills. Marmara University, Institue of Education Sciences, Doctoral Thesis, Istanbul.

Dwyer, J.J., \& Fischer, D.G. (1990): Wrestlers' perceptions of coaches' leadership as predictors of satisfaction with leadership. Percep. Motor Skill., 71(2):511-517.

French, J. \& Raven, B.H. (1959): The bases of social power. Cartwright, D. (Edt.), Studies in Social Power. Pub. by: Ann Arbor, Research Center for Group Dynamics, Institute for Social Research, University of Michigan.

Gayretli., Z. \& Çeli.k, A . (2020): Examined of Self-Leadership Behaviour of Sports Manager Candidates Whose Studied of Department of Sports Management. CBÜ Beden Egitimive Spor Bilimleri Dergisi , 15 (1) :18-30.
Kelman, H.C. (1958): Compliance, identification, and internalization: Three process of attitude change. J. Conf. Revol., 2:51-6o.

Kim, H.D., \& Cruz, A.B. (2016): The influence of coaches' leadership styles on athletes' satisfaction and team cohesion: A meta-analytic approach. Int. J. Sport. Sci. Coach., 11(6):900-909.

Konter, E. (2007): Perception of leaderhip power of coaches and athletes according to their gender. L. Phys. Edu. Sports Sci., 5(2):85-90.

Meydan, C.H. (2010): The Effects of Organizational Culture, Organizational Justice Perceptions on Organizational Commitment and Job Satisfaction: An Applied Research on Public Sector. Doctoral ThesisMilitary Academy, Institue of Defensive Science, Ankara.

Northouse, P.G. (2007): Leadership: Theory and practice (6th ed.). Thousand Oaks, California: Sage Publishing.on Leadership, Boston: Harvard Business School Press.

Öktem T. (2015): Review of Leadership Power Perceptions Based on the Personality Characteristics of Karete-do Athletes. Master Thesis. Celal Bayar UniversityInstiue of Social Sciences.

Reddin, W.J. (1977): An integration of leader-behaviour typologies. Group Organ. Stud., 2(3):282-295.

Slack, T.S. (1997): Understanding Sport Organizations, The Application of Organization Theory. Pub. by: Human Kinetics, IIIinois.

Toros, T. \&Tiryaki, S. (2006). Investigation of Validity and Reliability of Leadership Scale for Fotballers-Athlete's Perception of Coach's Behavior 9. International Sport Science Congress, 3-5 November 2006, Mugla, Turkey.

Tozkar, E. (2019): Examination of the Relationships Between Athlete Students' Perception of Leadership Power for Physical Education and Sports Teachers and Motivation for Success in Sports and Team Harmony. MuglaSitkiKoçmanUnivesity, Institue of Health Sciences, MasterThesis, Mugla.

Turman, P.D. (2001): Situational coaching styles: The impact of success and athlete maturity level on coaches' leadership styles over time. Small Group Res., 32(5):576-594.

Turman, P.D., \& Schrodt, P. (2004): New avenues for instructional communication research: Relationships among coaches' leadership behaviors and athletes' affective learning. Commun. Res. Rep., 21(2):130-143.

Turnnidge, J., \& Côté, J. (2019): Observing coaches' leadership behaviours: The development of the coach leadership assessment system (CLAS). Measur. Phys. Edu. Exerc. Sci., 23(3):214-226.

Wann, D.L., Metcalf, L.A., Brewer, K.R. \& Whiteside, H.D. (200o): Development of the power in sport questionnaires. J. Sport Behavior, 23(4):423-443.

Weiss, H.M. (2002): Deconstructing job satisfaction separating evaluations, beliefs and affective experiences. Human Res. Manag. Rev., 12(2):173-194.

Yukl, G. \& Falbe, C.M. (1991): Importance of different power sources in downward and lateral relations. J. App. Psychol., 76:416-423.

Zaleznik, A. (1998): Managers and leaders: Are they different?. Harvard Business Review. 